\title{
Inhibition of Cardiac Sympathetic Nerve Activity during Intravenous Administration of Lidocaine
}

\author{
Brian D. Miller, Marc D. Thames, and Allyn L. Mark, Cardiovascular Center, \\ Department of Internal Medicine, College of Medicine, University \\ of Iowa Hospitals and Clinics, Veterans Administration \\ Medical Center, Iowa City, Iowa 52242
}

\begin{abstract}
A B S T R A C T The antiarrhythmic action of lidocaine has been attributed solely to its direct electrophysiological effects on the heart. However, lidocaine is particularly effective in treating ventricular arrhythmias associated with increased sympathetic activity, e.g., in myocardial infarction and digitalis toxicity. We tested the hypothesis that lidocaine administered intravenously depresses cardiac sympathetic nerve activity (CSNA). We measured CSNA in six dogs in control state and after lidocaine in doses of $0.625,1.25$, and $2.5 \mathrm{mg} / \mathrm{kg}$ i.v. over $2 \mathrm{~min}$. These doses of lidocaine produced graded decreases of CSNA of $-8 \pm 2,-18 \pm 1$, and $-41 \pm 5 \%$, respectively $(P<0.05$, mean $\pm S E)$. In six additional experiments the bolus of lidocaine was followed by an infusion for $20 \mathrm{~min}(1.25 \mathrm{mg} / \mathrm{kg}$ followed by $100 \mu \mathrm{g} / \mathrm{kg}$ per min and $2.5 \mathrm{mg} / \mathrm{kg}$ followed by $200 \mu \mathrm{g} / \mathrm{kg}$ per min). Infusion of lidocaine maintained depression of CSNA at a level that was $23 \pm 3$ and $35 \pm 5 \%$ less than control $(P<0.05)$, respectively, at plasma lidocaine levels of $5.2 \pm 0.6$ and $7.5 \pm 1.4 \mu \mathrm{g} /$ $\mathrm{ml}$, respectively. CSNA returned to control during recovery periods. CSNA did not decrease with the passage of time or administration of vehicle. In five dogs with vagi intact, carotid sinuses isolated and held at a pressure of $100 \mathrm{mmHg}$, and aortic baroreceptors denervated, administration of lidocaine $(2.5 \mathrm{mg} / \mathrm{kg}$ followed by $200 \mu \mathrm{g} / \mathrm{kg}$ per min) decreased renal nerve activity to $71 \pm 8 \%$ of control. Increases in left ventricular systolic pressure and maximum derivative of pressure with respect to time $\left(d P / d t_{\max }\right)$ resulting from electrical stimulation of preganglionic sympathetic nerves were not significantly altered by lidocaine, but were markedly attenuated by hexamethonium, a ganglionic blocker.
\end{abstract}

\footnotetext{
Address reprint requests to Dr. Mark.

Received for publication 8 March 1982 and in revised form 28 December 1982.
}

In conclusion, lidocaine administered intravenously produces dose-dependent and sustained decreases in cardiac sympathetic nerve activity. These decreases can occur with therapeutic plasma levels. We speculate that this effect is due to central nervous system effects of the drug and that this effect may contribute to the antiarrhythmic actions of lidocaine.

\section{INTRODUCTION}

The antiarrhythmic action of lidocaine has generally been attributed solely to its direct electrophysiologic effects on the heart. Lidocaine is particularly effective in the prevention and treatment of ventricular arrhythmias associated with digitalis intoxication (1-3), myocardial ischemia (4), and administration of certain anesthetic agents (5). These arrhythmias may result in part from increases in cardiac sympathetic activity $(6,7)$. This prompted us to consider the possibility that lidocaine administered intravenously inhibits cardiac sympathetic nerve activity and that this action might contribute to its antiarrhythmic effects.

Several observations lend credence to this hypothesis. First, lidocaine is a local anesthetic agent that produces central neural effects when administered systemically. Second, as noted above, lidocaine is particularly effective in the treatment of arrhythmias associated with increased sympathetic nerve activity (1$5)$. Third, hypotension and bradycardia have been reported following systemic administration of lidocaine $(8,9)$; these effects could relate partly to a sympatholytic effect of the drug. The goal of this study was to test the hypothesis that lidocaine administered intravenously inhibits efferent cardiac sympathetic nerve activity.

\section{METHODS}

\section{General}

Mongrel dogs (18-25 kg) were anesthetized with sodium pentothal $(25 \mathrm{mg} / \mathrm{kg}$ i.v.) and $\alpha$-chloralose $(80$ and $10 \mathrm{mg} /$ 
$\mathrm{kg}$ hourly i.v.). After endotracheal intubation, the dogs were mechanically ventilated with room air supplemented with oxygen at 12-16 cycles/min with a tidal volume of $17 \mathrm{ml} /$ kg. Arterial oxygen tension $\left(\mathrm{Po}_{2}\right)$, carbon dioxide tension $\left(\mathrm{CO}_{2}\right)$, and $\mathrm{pH}$ were measured at intervals, and when necessary, were corrected by adjustment of respiratory frequency or administration of $\mathrm{NaHCO}_{3}$. Body temperature was maintained by external warming.

Arterial pressure was measured with a cannula inserted via the right femoral artery connected to a Statham P23dB transducer (Statham Instruments, Inc., Oxnard, CA). Mean arterial pressure was obtained by electrical averaging of the pulsatile signal. Heart rate was measured with a cardiotachometer preamplifier triggered by the arterial pressure pulse.

\section{Recording of cardiac sympathetic nerve activity}

Through a left thoracotomy, the left caudal cervical ganglion was identified. The cardiac nerves distal to the ganglion were exposed. One of the nerves (usually the ventrolateral cardiac nerve) was cut distally and separated from adjacent tissues. The central end of the nerve was placed in a small cup filled with mineral oil. After removing the sheath, the nerve was placed on a bipolar $\mathrm{Ag}$-AgCl electrode for recording of cardiac efferent sympathetic nerve activity. Nerve activity was recorded with bipolar $\mathrm{Ag}$ - $\mathrm{AgCl}$ electrodes connected to a Grass high impedance probe (HIP 511E) and amplified by a Grass (P511G) band pass amplifier (Grass Instrument Co., Quincy, MA). The high and low frequency cutoffs were set at 1,000 and $30 \mathrm{~Hz}$, respectively. The amplifier output was audible over a Grass audiomonitor and visualized on a Tektronic oscilloscope (Tektronix, Inc., Tarrytown, NY). The output was also led into a nerve traffic analyzer that counted spike potentials exceeding a selected voltage (usually just above the noise). Each action potential exceeding the voltage setting of the window discriminator was rectified and integrated. The rising phase of each action potential triggered the rectified signal. Thus, the quantification of the activity was independent of the amplitude of the individual spikes. The counter was digital in design, and the relationship between integrator output and spike frequency was linear up to $10 \mathrm{kHz}$. A counter of similar design has been used previously in our laboratories in the quantitation of multiunit cardiac sympathetic nerve activity (10). The integrated nerve activity and hemodynamic measurements were recorded continuously on a Beckman R411 physiologic recorder (Beckman Instruments, Inc., Fullerton, CA). The dogs were treated with decamethonium bromide $(0.3$ $\mathrm{mg} / \mathrm{kg}$ i.v.) to prevent muscle movement. In five dogs nerve activity was recorded from the renal rather than the cardiac sympathetic nerves as previously described (11).

\section{Baroreceptor debuffering}

We excluded the influence of arterial baroreceptors in most experiments (groups I-III) to minimize baroreflex buffering and to exclude an effect of lidocaine on baroreceptors. Both aortic depressor and vagus nerves were cut in groups I-III. In group I (six experiments) reflex effects mediated by carotid baroreceptors were minimized by ligating the common carotid arteries. In groups II and III (nine experiments) reflex effects of carotid baroreceptors were eliminated by sectioning the carotid sinus nerves. Efficacy of carotid sinus denervation was established by blockade of the pressor and heart rate responses to bilateral carotid occlusion. Thus, responses to lidocaine were independent of reflex responses mediated by arterial baroreflexes or by cardiopulmonary baroreflexes with vagal afferent pathways.

The responses to intravenous lidocaine were assessed in an additional group of five dogs (group IV) with vagi intact, aortic nerves sectioned, and carotid sinus regions isolated from the circulation at a pressure of $100 \mathrm{~mm} \mathrm{Hg}$.

\section{Preganglionic cardiac sympathetic nerve stimulation}

A left thoracotomy was performed through the third intercostal space so as to expose the left ansa subclavia and the left stellate ganglion. The third and fourth thoracic preganglionic nerves were freed from surrounding tissue, cut centrally and placed on stimulating electrodes. The remainder of the nerves leading into the stellate ganglion was sectioned. The preganglionic sympathetic nerves were stimulated with a Grass stimulator at frequencies of 0.25 to $2.0 \mathrm{~Hz}, 35 \mathrm{~V}$, and $4 \mathrm{~ms}$. In these experiments we recorded left ventricular pressure with a Königsberg solid state pressure transducer. The signal was differentiated to obtain maximum derivative of pressure with respect to time $\left(d P / d t_{\max }\right) .^{1}$

\section{Lidocaine and plasma lidocaine level determination}

Stock solutions of 2 and $4 \%$ lidocaine hydrochloride were used to prepare lidocaine for injection and infusion. Plasma lidocaine levels were determined using the EMIT lidocaine immunoenzymatic assay on an IL Multistat III Centrifugal Analyzer as described by Cobb et al. (12).

\section{Protocols}

Group I: bolus lidocaine $(n=6)$. The protocol was started after a 30-min equilibration period. Six dogs each received three doses $(0.625,1.25$, and $2.5 \mathrm{mg} / \mathrm{kg})$ of lidocaine with each administered intravenously over $2 \mathrm{~min}$. Each dose was diluted with normal saline to obtain a constant injection volume of $10 \mathrm{~cm}^{3}$. The order of administration of doses was randomized. At the time of maximal response of nerve activity a $12-\mathrm{cm}^{3}$ arterial blood sample was obtained to determine plasma lidocaine concentration. The maximal response occurred within 2 min after the end of the injection. A 30 min recovery period was interposed between the administration of each dose of lidocaine and the withdrawal of a subsequent blood sample. The heart rate, blood pressure, and nerve activity at the end of the 30 -min recovery period served as the control for the next dose. In these six experiments, the responses to an equivalent volume of saline also was determined. The order of vehicle administration was randomized with the lidocaine administrations.

Group II: bolus and infusion of lidocaine $(n=6)$. Six dogs received each of three loading doses of lidocaine (over $4 \mathrm{~min}$ ) followed by a $20-\mathrm{min}$ infusion of lidocaine: $1.25-\mathrm{mg} /$ $\mathrm{kg}$ loading dose and $100-\mu \mathrm{g} / \mathrm{kg}$ per min infusion (low dose); $2.5 \mathrm{mg} / \mathrm{kg}$ and $200 \mu \mathrm{g} / \mathrm{kg}$ per min (middle dose); and 3.75 $\mathrm{mg} / \mathrm{kg}$ and $300 \mu \mathrm{g} / \mathrm{kg}$ per min (high dose). The order of

\footnotetext{
${ }^{1}$ Abbreviations used in this paper: CSNA, cardiac sympathetic nerve activity; $d P / d t_{\max }$, maximum derivative of pressure with respect to time.
} 
administration of these dosage combinations was determined using a latin square design. A 30 -min recovery was interposed between the end of the 20 -min infusion and the beginning of the next bolus-infusion combination. A $12-\mathrm{cm}^{3}$ arterial blood sample for plasma lidocaine determination was obtained at the end of the 4-min loading dose, after the 20min infusion, and following a $30-\mathrm{min}$ recovery period.

Group III: bolus and infusion of vehicle $(n=3)$. Three dogs received a 4-min injection of saline followed by a 20 min infusion of saline; volumes administered were equal to the volume of vehicle administered in group II. Blood samples were taken at the end of the bolus and the infusion.

Group IV: bolus and infusion of lidocaine $(n=5)$. Five dogs with aortic baroreceptor denervation, vagi intact, and carotid sinus isolated and held at a constant pressure of 100 $\mathrm{mmHg}$, received a bolus of lidocaine $(2.5 \mathrm{mg} / \mathrm{kg})$ over $2 \mathrm{~min}$ followed by a $20-\mathrm{min}$ infusion of $200 \mu \mathrm{g} / \mathrm{kg}$ per min. A blood sample for plasma lidocaine determination and responses to lidocaine were obtained at the end of the infusion and after a 20-min recovery period. In these studies we recorded renal rather than cardiac sympathetic nerve activity.

Group V: effects of lidocaine on ganglionic transmission $(n=4)$. As noted below, we observed decreases in postganglionic sympathetic nerve activity during lidocaine administration. A possible explanation for these decreases in postganglionic nerve activity was an inhibitory action on ganglionic transmission. To determine if lidocaine was interfering with ganglionic transmission, we measured responses of left ventricular systolic pressure and $d P / d t_{\max }$ to electrical stimulation of preganglionic cardiac sympathetic nerves. Responses to stimulation at $0.25,0.5,1.0$, and $2.0 \mathrm{~Hz}$ were obtained in $(a)$ control state, $(b)$ during lidocaine administration, $(c)$ after 60 min recovery from lidocaine administration, and $(d)$ after ganglionic blockade. Stimulation at each frequency was performed for $45 \mathrm{~s}$ with $3 \mathrm{~min}$ interposed between successive periods of stimulation. These experiments were carried out with arterial baroreflexes and vagi intact.

After obtaining control responses, a $2.5-\mathrm{mg} / \mathrm{kg}$ bolus of lidocaine was administered intravenously over $4 \mathrm{~min}$ followed by a sustaining infusion of lidocaine at $200 \mu \mathrm{g} / \mathrm{kg}$ per min. Responses to preganglionic stimulation again were obtained $10 \mathrm{~min}$ after the infusion was started; at this time a blood sample was obtained for plasma lidocaine determination. A third series of responses to preganglionic stimulation was obtained $60 \mathrm{~min}$ after stopping the infusion of lidocaine.

To determine the extent to which the response seen with preganglionic nerve stimulation was dependent on ganglionic transmission, $10 \mathrm{mg} / \mathrm{kg}$ i.v. hexamethonium bromide was administered over $30 \mathrm{~min}$ to block ganglionic transmission and responses to preganglionic sympathetic nerve stimulation again were measured. The dose of hexamethonium we used blocked the pressor response to bilateral carotid occlusion (baroreflexes were intact in these experiments).

\section{Statistics}

The changes in cardiac sympathetic nerve activity were expressed as a percent change from the control level. Changes in blood pressure and heart rate were expressed and analyzed as absolute changes from control levels.

Group I. These data are the peak changes in cardiac sympathetic nerve activity (CSNA), heart rate, and mean arterial pressure observed over $30 \mathrm{~s}$ following bolus lidocaine administration.
Groups II, III, and IV. The results reported for the infusion protocols are the differences in CSNA, heart rate, and mean arterial pressure between a 60 -s time period at the end of the infusion and a comparable period of time just before bolus administration.

Group $V$. We compared the absolute changes in peak systolic left ventricular pressure and $d P / d t_{\max }$ observed during stimulation at $0.25,0.50,1.0$, and $2.0 \mathrm{~Hz}$ to those observed during a control period and during lidocaine administration. The responses after treatment with hexamethonium were compared with those recorded just prior to hexamethonium administration.

The significance of changes within and between groups was assessed by analysis of variance or by Student's $t$ test when paired comparisons were made. Differences were considered significant for $P \leq 0.05$. Data are presented in the text and figures as mean $\pm S E$.

\section{RESULTS}

Group I: bolus lidocaine. These studies examined the responses to lidocaine $0.625,1.25$, and $2.5 \mathrm{mg} / \mathrm{kg}$ and to vehicle. Control values before each of the three doses of lidocaine did not differ significantly. Control values of CSNA averaged $26 \pm 9,26 \pm 12$, and $24 \pm 9 \mathrm{im}$ pulses/s before the low, middle, and high doses, respectively. Corresponding values for control mean arterial pressure were $163 \pm 16,159 \pm 20$, and $170 \pm 19$ $\mathrm{mmHg}$, respectively.

Lidocaine, $0.625,1.25$, and $2.5 \mathrm{mg} / \mathrm{kg}$, produced dose-dependent decreases in CSNA averaging $-8 \pm 1$, $-18 \pm 1$, and $-41 \pm 5 \%$, respectively (Fig. 1). Corresponding plasma lidocaine levels were $7.2 \pm 1.5$, $10.5 \pm 2.6$, and $22.3 \pm 3.3 \mu \mathrm{g} / \mathrm{ml}$, respectively. A signif-
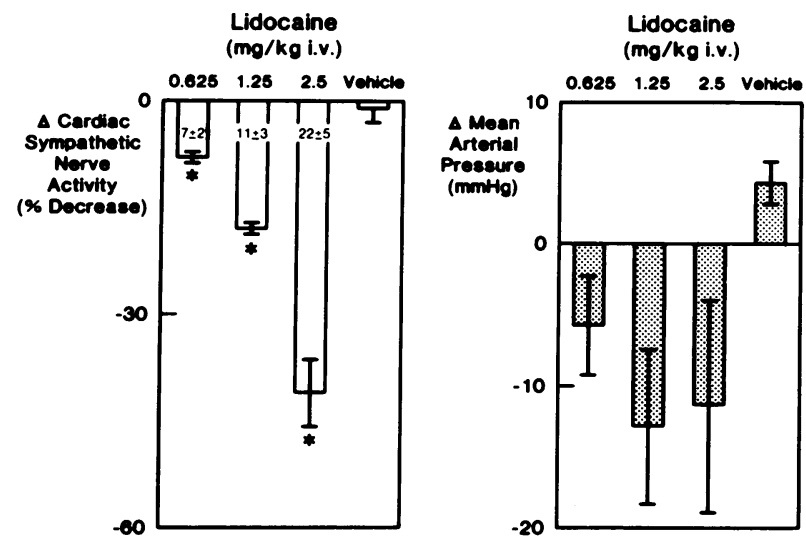

FIGURE 1 Changes in cardiac sympathetic nerve activity (left) and mean arterial pressure (right) in response to bolus intravenous administration of lidocaine. The dose of lidocaine in each bolus is shown above each graph. Plasma lidocaine levels drawn at the time that the observations were made are indicated within the bars (micrograms per milliliter). Significant changes from control are so indicated and were determined by analysis of variance. $P<0.05$, mean $\pm \mathrm{SE}, n=6$. The responses to administration of vehicle also are shown. 
icant decrease in heart rate occurred only with the highest dose of lidocaine: $-8.2 \pm 2.8$ beats $/$ min. Mean arterial pressure tended to fall with all three doses (Fig. 1), but was significantly reduced only with the $1.25-\mathrm{mg} / \mathrm{kg}$ bolus: $-13.6 \pm 6 \mathrm{mmHg}$. CSNA returned to values not different from control during the recovery period (Fig. 1). Plasma levels of lidocaine at the end of the recovery periods averaged $1.0 \pm 0.4,1.0 \pm 0.3$, and $1.1 \pm 0.2 \mu \mathrm{g} / \mathrm{ml}$, respectively. A record illustrating the response of integrated cardiac sympathetic nerve activity to bolus injection of lidocaine is shown in Fig. 2A.

Administration of vehicle did not change CSNA or heart rate, but was associated with a small but significant increase in arterial pressure $(4.1 \pm 1.7 \mathrm{mmHg})$ (Fig. 1).

Groups II and III: bolus + infusion of lidocaine or vehicle. The studies in group II examined the responses to bolus followed by sustained infusions of lidocaine in six dogs. The doses of the bolus and infusion were $1.25 \mathrm{mg} / \mathrm{kg}$ bolus and $100 \mu \mathrm{g} / \mathrm{kg}$ per min infusion; $2.5 \mathrm{mg} / \mathrm{kg}$ bolus and $200 \mu \mathrm{g} / \mathrm{kg}$ per min infusion; and $3.75 \mathrm{mg} / \mathrm{kg}$ bolus and $300 \mu \mathrm{g} / \mathrm{kg}$ per min infusion. Bolus injection and subsequent infusion of vehicle were performed in three sham experiments (group III). A record illustrating the response of integrated cardiac sympathetic nerve activity to bolus and infusion of lidocaine is shown in Fig. 2B.

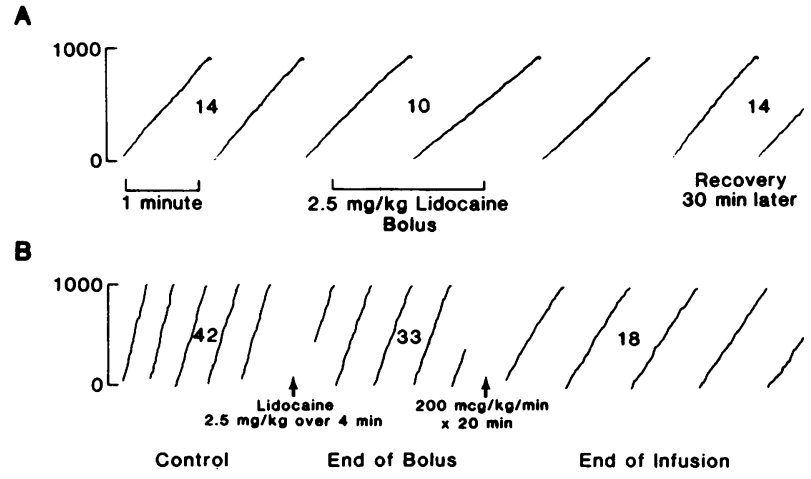

Figure 2 Integrated cardiac sympathetic nerve activity (impulses). Records illustrating the response of integrated sympathetic nerve activity to intravenous lidocaine (plasma lidocaine levels within bars measured in micrograms per milliliter). A: Response to bolus injection of $2.5 \mathrm{mg} / \mathrm{kg}$ i.v. of lidocaine. During the control period, activity averaged 14 spikes/s. After bolus lidocaine administration, activity decreased to 10 spikes/s. $30 \mathrm{~min}$ after administration of the bolus, activity returned to control. B: Response of integrated cardiac sympathetic nerve activity to bolus lidocaine administration followed by infusion of lidocaine. Integrated sympathetic nerve activity was 42 spikes/s during the control period, and 33 spikes/s at the end of the bolus, and 18 spikes/ $s$ at the end of the infusion.
In group II, control values before the three combinations of lidocaine did not differ significantly. Control values of CSNA averaged $23 \pm 8,20 \pm 9$, and $18 \pm 7 \mathrm{im}-$ pulses/s before the low, middle, and high doses, respectively. Corresponding values for mean arterial pressure were $145 \pm 14,162 \pm 11$, and $163 \pm 18 \mathrm{mmHg}$, respectively.

Bolus injection of the low, middle, and high doses of lidocaine resulted in decreases in CSNA averaging $-17 \pm 3,-24 \pm 4$, and $-25 \pm 5 \%$, respectively (Fig. 3). At the end of the 20-min infusion, the decreases averaged $-23 \pm 5,-35 \pm 5$, and $-36 \pm 13 \%$, respectively (Fig. 3). Corresponding plasma lidocaine levels were $7.9 \pm 1.5,10.9 \pm 1.8$, and $16.9 \pm 1.7 \mu \mathrm{g} / \mathrm{ml}$, respectively, during the bolus and $5.2 \pm 0.6,7.5 \pm 1.4$, and $9.3 \pm 1.0$ $\mu \mathrm{g} / \mathrm{ml}$, respectively at the end of the infusion. There was a significant decrease in heart rate $(-14 \pm 4$ beats/ min) only with the highest bolus dose of lidocaine; but significant decreases in heart rate were also observed at the end of the infusion of the low dose $(-3 \pm 1$ beats/ $\mathrm{min})$ and high dose $(-15.3 \pm 1.6$ beats $/ \mathrm{min})$. Although there was a tendency for arterial pressure to decrease during both the bolus and the infusion, the changes did not reach statistical significance. During the recovery period CSNA returned to levels not significantly different from control.

In group III, heart rate and blood pressure did not change significantly with the administration of vehicle. There was a tendency for CSNA to increase during

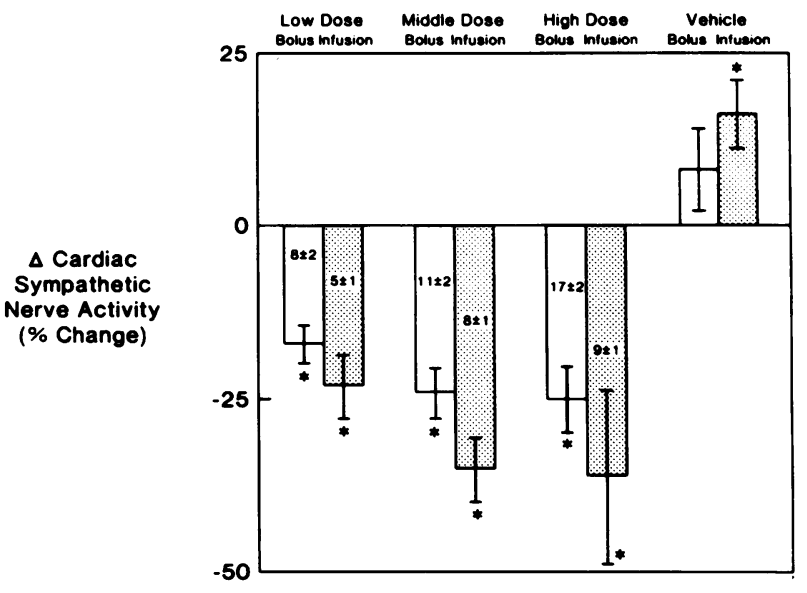

Figure 3 Changes in cardiac sympathetic nerve activity resulting from bolus injection of lidocaine (open bars) followed by a sustained infusion of lidocaine (stippled bars) in six experiments. Significant changes $(P<0.05)$ from control are indicated by asterisks and were determined by analysis of variance. Plasma lidocaine levels that were obtained at the time that these changes in cardiac sympathetic nerve activity were detected are indicated within the bars. Responses to bolus injection of vehicle and subsequent infusion of vehicle in three separate experiments also are shown. 
the bolus injections of vehicle and it was increased significantly at the end of the 20 minute infusion (+15.8 44.7\%; Fig. 3). These changes in levels of CSNA were significantly different from those changes observed during lidocaine administration.

Group IV. These experiments determined if lidocaine decreased renal sympathetic nerve activity when tonic inhibition of the vasomotor centers by vagal cardiopulmonary and carotid baroreflexes (aortic baroreceptor denervation) was present. Control renal nerve activity was $67 \pm 14 \mathrm{impulses} / \mathrm{s}$. Activity fell to $71 \pm 8 \%$ of this level after lidocaine $(P<0.05)$ and returned to $94 \pm 4 \%$ of control $30 \mathrm{~min}$ after cessation of drug administration. Plasma lidocaine levels averaged $6 \pm 2$ $\mu \mathrm{g} / \mathrm{ml}$. These decreases in nerve activity during lidocaine were not accompanied by significant changes in heart rate or arterial pressure. Heart rate averaged $176 \pm 10$ in control, $173 \pm 13$ during lidocaine, and $172 \pm 15$ beats/min in recovery. Mean arterial pressure averaged $148 \pm 12$ in control, $128 \pm 12$ during lidocaine, and $112 \pm 14 \mathrm{mmHg}$ during recovery.

Group V. These experiments examined the effect of lidocaine on the cardiac responses to preganglionic cardiac sympathetic nerve stimulation at frequencies of $0.25,0.5,1.0$, and $2.0 \mathrm{~Hz}$. The responses of left ventricular systolic pressure and $d P / d t_{\max }$ were determined before and after lidocaine $(2.5 \mathrm{mg} / \mathrm{kg}$ bolus followed by $200 \mu \mathrm{g} / \mathrm{kg}$ per min infusion) administration. Control values of systolic pressure and $d P / d t_{\max }$ averaged $165 \pm 8$ and $2,255 \pm 553 \mathrm{mmHg} / \mathrm{s}$ before li- docaine and $186 \pm 12 \mathrm{mmHg}$ and $3,117 \pm 526 \mathrm{mmHg} /$ $s$ after lidocaine administration $(P<0.05)$. Preganglionic nerve stimulation produced frequency dependent increases in left ventricular systolic pressure and $d P / d t_{\max }($ Table I). These increases were not attenuated by lidocaine (Table I). Control values of left ventricular systolic pressure and $d P / d t_{\max }$ averaged $185 \pm 10$ and $2,961 \pm 563 \mathrm{mmHg} / \mathrm{s}$ before and $137 \pm 8$ and $2,301 \pm 316 \mathrm{mmHg} / \mathrm{s}$ after treatment with hexamethonium $(P<0.05)$. In contrast to the responses observed with lidocaine, hexamethonium bromide significantly attenuated the increases in left ventricular systolic pressure and $d P / d t_{\max }$ pressure during preganglionic stimulation (Table I).

\section{DISCUSSION}

The principal finding in this study is that lidocaine administered intravenously produces dose-dependent and sustained decreases in efferent postganglionic cardiac sympathetic nerve activity in the debuffered dog. These decreases in CSNA were not related to time or deterioration of the preparation since decreases were not observed with administration of the vehicle. Similar effects on renal sympathetic nerve active were also seen in dogs with vagi intact and carotid baroreceptor input held constant.

What is the mechanism by which lidocaine decreases CSNA? We considered effects on $(a)$ afferent mechanisms, $(b)$ efferent mechanisms, and $(c)$ central neural mechanisms.

TABLE I

Effects of Lidocaine and Hexamethonium on Increases in Left Ventricular Systolic Pressure and $d P / d t_{\max }$ during Preganglionic Sympathetic Nerve Stimulation

\begin{tabular}{|c|c|c|c|c|}
\hline \multirow[b]{2}{*}{ Frequency of stimulation } & \multicolumn{4}{|c|}{ Increases in left ventricular systolic pressure, $\mathrm{mmHg}$} \\
\hline & $\begin{array}{l}\text { Control } \\
\text { responses }\end{array}$ & $\begin{array}{l}\text { Responses during } \\
\text { lidocaine }\end{array}$ & $\begin{array}{l}\text { Control } \\
\text { responses }\end{array}$ & $\begin{array}{l}\text { Responses after } \\
\text { hexamethonium }\end{array}$ \\
\hline $\mathrm{Hz}$ & \multicolumn{2}{|c|}{. } & & \\
\hline 0.25 & $9 \pm 1.9$ & $7 \pm 1.2$ & $7 \pm 1.8$ & $1 \pm 0.8^{\circ}$ \\
\hline 0.50 & $12 \pm 6.5$ & $18 \pm 9.0$ & $15 \pm 4.8$ & $4 \pm 2.2^{\circ}$ \\
\hline 1.00 & $25 \pm 4.8$ & $18 \pm 3.5$ & $21 \pm 6.7$ & $9 \pm 5.4^{\circ}$ \\
\hline \multirow[t]{2}{*}{2.00} & $29 \pm 9.0$ & $33 \pm 3.6$ & $29 \pm 7.7$ & $12 \pm 6.5^{\circ}$ \\
\hline & \multicolumn{4}{|c|}{ Percent increases in left ventricular $d P / d t_{\text {max }}$} \\
\hline 0.25 & $3 \pm 2$ & $5 \pm 1$ & $4 \pm 2$ & $1 \pm 1^{\circ}$ \\
\hline 0.50 & $12 \pm 4$ & $12 \pm 5$ & $18 \pm 5$ & $2 \pm 1^{\circ}$ \\
\hline 1.00 & $26 \pm 4$ & $24 \pm 7$ & $23 \pm 6$ & $9 \pm 5^{\circ}$ \\
\hline 2.00 & $34 \pm 6$ & $38 \pm 8$ & $37 \pm 5$ & $9 \pm 2^{\circ}$ \\
\hline
\end{tabular}

$\mathbf{n}=4$.

Mean \pm SE.

- $P<0.05$ (responses after lidocaine or hexamethonium compared to corresponding control responses). 
Thoren and Oberg (13) have reported that intravenous administration of lidocaine in cats "anesthetizes" or desensitizes cardiac mechanoreceptors with nonmedullated afferent vagal fibers. This endoanesthetic effect could influence sensory endings throughout the heart and great vessels. However, our results cannot be explained by an anesthetic effect on vagal, aortic, or carotid afferent fibers since many of our studies were done after sinoaortic denervation and vagotomy.

Cardiac sensory receptors with sympathetic afferent pathways can mediate excitatory influences on efferent sympathetic activity $(14,15)$. It is possible that an anesthetic effect of lidocaine on excitatory sympathetic afferent fibers might have decreased CSNA. We doubt that it is the major mechanism for the decreased CSNA for the following reason. We have recorded renal sympathetic nerve activity in eight dogs with vagi sectioned and sinoaortic baroreceptor denervation before and after section of the stellate ganglia and first four thoracic white rami bilaterally (unpublished observations). Activity averaged $65 \pm 32$ impulses/s before and $66 \pm 37$ impulses/s after cardiac sympathetic deafferentation. We could detect no tonic excitatory influence of cardiac sympathetic afferents on renal sympathetic outflow. Moreover, recent evidence indicates that cardiac receptors with sympathetic afferents frequently mediate inhibitory responses in dogs (11). Thus, it seems unlikely that inhibition of cardiac sympathetic nerve activity is due to removal of a tonic excitatory influence because of endoanesthesia.

Evans and Gillis (16) reported that intravenous administration of lidocaine in cats prevented the arrhythmias induced by electrical stimulation of the hypothalamus. These investigators suggested that lidocaine might be acting on peripheral neural sites, i.e., ganglionic or postganglionic sites. In view of the suggestions of Evans and Gillis, we evaluated the possibility that the decreases in postganglionic CSNA that we observed might be due to inhibition of ganglionic transmission by lidocaine. To test this hypothesis, we measured responses to preganglionic cardiac sympathetic nerve stimulation before and after lidocaine. Lidocaine in doses that decreased postganglionic nerve activity did not decrease responses to preganglionic stimulation. In the same experiments hexamethonium, a ganglionic blocking agent, markedly decreased these responses. These results indicate that the depression in postganglionic nerve activity produced by lidocaine did not result from depression of ganglionic transmission. The observation of Evans and Gillis (15) that lidocaine did not alter preganglionic sympathetic nerve responses to hypothalamic stimulation does not exclude a central nervous mechanism for the effect of lidocaine we observed. First, Evans and Gillis exam- ined responses to stimulation of a discrete area of the brain, whereas lidocaine could have its major influence at some central locus "upstream" of these neurons. Second, we examined the influence of lidocaine on tonic sympathetic activity while they examined the responses to a specific intervention. Changes in tonic activity need not be accompanied by changes in response to hypothalamic stimulation.

We speculate that lidocaine acts in the central nervous system or spinal cord to inhibit sympathetic nerve activity. Lidocaine rapidly crosses the blood brain barrier to the central nervous system (17) and is known to alter central neural mechanisms. Gillis et al. (18) reported that methyl-lidocaine, which purportedly does not cross the blood brain barrier, prevents the arrhythmias produced by sympathetic excitation. Based on this finding, Gillis et al. (18) implied that the effect of lidocaine on these arrhythmias is not dependent on a central neural effect. However, it is now known that small regions of the brain that are devoid of the blood brain barrier may be critically important in regulation of sympathetic activity (19). Thus, the observations with methyl-lidocaine do not exclude a central neural action of lidocaine.

In this study the depression of sympathetic nerve activity was maintained during the sustained infusion although the plasma levels of lidocaine were lower than those following the loading dose. We speculate that this persistent inhibition of nerve activity at low plasma lidocaine levels may relate to the time course of diffusion and/or active transport of lidocaine into the cerebrospinal fluid and brain $(17,19,20)$.

We should comment briefly on the significant increase in sympathetic nerve activity seen $20 \mathrm{~min}$ after administration of the vehicle, which was $10 \mathrm{ml}$ of saline (Fig. 3). We doubt that this was an effect of vehicle per se since this was not observed when responses were obtained $2 \mathrm{~min}$ after administration of the same amount of vehicle (Fig. 1). Instead, we suspect that this increase in nerve activity represents an effect of time in this preparation. Whatever the mechanism, this increase in nerve activity with the vehicle and time contrasts sharply with the decreases observed after lidocaine. This suggests that with the sustained infusion the inhibitory influence of lidocaine may be even greater than that judged by the decreases from control values.

It is tempting to speculate that inhibition of cardiac sympathetic nerve activity could contribute to the antiarrhythmic action of lidocaine. As mentioned previously, lidocaine is particularly effective in the treatment of ventricular arrhythmias associated with increased sympathetic activity such as those related to myocardial infarction (4) and digitalis intoxication (1, $2)$. In addition, it is known that inhibition of sympa- 
thetic influences by cardiac denervation $(21,22)$ can protect against these types of arrhythmias. Thus, there is reason to suggest that inhibition of sympathetic nerve activity by lidocaine might contribute to its antiarrhythmic actions. We would emphasize, however, that this study has not tested the contribution of inhibition of sympathetic nerve activity to the antiarrhythmic effect of lidocaine.

In view of our speculation that lidocaine acts in the central nervous system to inhibit sympathetic nerve activity, it is interesting to note two recent preliminary reports by Zito et al. $(23,24)$. These investigators reported that lidocaine given systemically protects mice against ventricular fibrillation induced by chloroform. Lidocaine also reduced brainstem serotonin metabolism. When this effect was prevented by pretreatment with parachloramphetamine, the antiarrhythmic effect of lidocaine was reduced. These observations support the concept that lidocaine might produce central neural effects that contribute to its antiarrhythmic action.

In conclusion, this study demonstrates that intravenous administration of lidocaine produces dose-dependent and sustained inhibition of cardiac sympathetic nerve activity in the dog. We speculate that this effect results from a central nervous system influence of lidocaine.

\section{ACKNOWLEDGMENTS}

We would like to acknowledge the research assistance of Ralph Richter and Steve Yuih, and the secretarial assistance of Jan Ellsworth and Deborah Ecker.

This work was performed during a Stanley Sarnoff Cardiovascular Science Research Fellowship (Brian D. Miller). Research support for this project was provided by funding from the Veterans Administration and by research grants HL24962 and HL21158 and Program Project Grant HL14388 from the National Institutes of Health. Dr. Thames is the recipient of a Research Career Development Award from the National Institutes of Health.

\section{REFERENCES}

1. Hilmi, K. I. and T. J. Regan. 1968. Relative effectiveness of antiarrhythmic drugs in treatment of digitalis induced ventricular tachycardia. Am. J. Cardiol. 76: 365-369.

2. Paradise, R. R. 1967. Antiarrhythmic activity of lidocaine and $\mathrm{N}$-isopropyl-p-nitrophenylethanolamine (INPEA) in acetylstrophanthidin-induced arrhythmias. Arch. Int. Pharmacodyn. 169: 482-493.

3. Usubiaga, J. E., J. A. Wikinski, B. Bestal, and F. Moya. 1968. The effect of lidocaine pretreatment of digitalis intoxication. Anes. Anal. 47: 192-198.

4. Jewitt, D. E., Y. Kishan, and M. Thomas. 1968. Lignocaine in the management of arrhythmias after acute myocardial infarction. Lancet. I: 266-270.

5. Weiss, W. A. 1960. Intravenous use of lidocaine for ventricular arrhythmias. Anes. Anal. 39: 369-381.

6. Gillis, R. A., A. Raines, Y. J. Sohn, B. Levitt, and R. G.
Standert. 1972. Neuroexcitatory effects of digitalis and their role in the development of cardiac arrhythmias. J. Pharmacol. Exp. Ther. 183: 154-168.

7. Webb, S. W., A. A. J. Adgey, and J. F. Pantridge. 1972 Autonomic disturbances at onset of acute myocardial infarction. Br. Med. J. 3: 89-92.

8. Austen, W. G., and J. M. Moran. 1965. Cardiac and peripheral vascular effects of lidocaine and procainamide. Am. J. Cardiol. 16: 701-707.

9. Haggart, J., and L. Woods. 1951. Mechanism of the depressor action of procaine, lidocaine, and cocaine in etherized dogs. J. Pharmacol. Exp. Ther. 103: 345 (Abstr.)

10. Felder, R. B., and M. D. Thames. 1981. The cardiocardiac sympathetic reflex during coronary occlusion in anesthetized dogs. Circ. Res. 48: 685-692.

11. Felder, R. B., and M. D. Thames. 1982: Responses to activation of cardiac sympathetic afferents with epicardial bradykinin. Am. J. Physiol. 242: H148-H153.

12. Cobb, M. E., N. Buckley, M. W. Hu, J. G. Miller, P. Singh, and R. S. Scheider. 1977. Homogenous enzyme immunoassay for lidocaine in serum. Clin. Chem. 23: 1161.

13. Thoren, P., and B. Oberg. 1981. Studies on the endoanesthetic effects of lidocaine and benzonatate on nonmedullated nerve endings in the left ventricle. Acta Physiol. Scand. 111: 51-58.

14. Malliani, A., and F. Lombardi. 1979. Neural reflexes associated with myocardial ischemia. In Neural Mechanisms in Cardiac Arrhythmias. P. J. Schwartz, A. M. Brown, A. Malliani, and A. Zanchetti, editors. Raven Press, New York. 209-219.

15. Malliani, A., P. J. Schwartz, and A. Zanchetti. 1969. A sympathetic reflex elicited by experimental coronary occlusion. Am. J. Physiol. 217: 703-709.

16. Evans, D. E., and R. A. Gillis. 1974. Effect of DPH and lidocaine on cardiac arrhythmias induced by hypothalamic stimulation. J. Pharmacol. Exp. Ther. 191: 506514.

17. Spector, R. 1980. Transport of lignocaine by rabbit choroid plexus in vitro. Clin. Sci. 58: 107-109.

18. Gillis, R. A., F. H. Levine, H. Thibodeaux, A. Raines, and F. G. Standert. 1973. Comparison of methyl-lidocaine and lidocaine on arrhythmias produced by coronary occlusion in the dog. Circulation. 47: 697-703.

19. Ferrario, C. M., P. L. Gildenberg, and J. W. McCubbin. 1972. Cardiovascular effects of angiotensin mediated by the central nervous system. Circ. Res. 30: 257-262.

20. Usubiaga, J. E., F. Moya, J. A. Wikinski, R. Wikinski, and L. E. Usubiaga. 1967. Relationship between the passage of local anesthetics across the blood brain barrier and their effects on the central nervous system. $B r . J$. Anesthesia. 39: 943-945.

21. Boyajy, L. D., and C. B. Nash. 1966. Alteration of ouabain toxicity by cardiac denervation. Toxicol. Appl. Pharmacol. 9: 199-208.

22. Erlij, D., and R. Mendez. 1964. The modification of digitalis intoxication by excluding adrenergic influences on the heart. J. Pharmacol. Exp. Ther. 144: 97-103.

23. Zito, R. A., D. K. Riker, A. Gurkan, and M. Cleman. 1982. Lidocaine reduces brainstem serotonin metabolism and protects mice from chloroform-induced ventricular fibrillation. Clin. Res. 30: 232a. (Abstr.)

24. Zito, R. A., K. Culver, and M. Cleman. 1982. Brainstem serotonin depletion reduces lidocaine protection against chloroform-induced ventricular fibrillation in mice. Circulation. 66: II-308. 